\title{
Erratum to: "FearNot!": a computer-based anti-bullying-programme designed to foster peer intervention
}

\author{
Natalie Vannini • Sibylle Enz • Maria Sapouna • \\ Dieter Wolke • Scott Watson • Sarah Woods • \\ Kerstin Dautenhahn • Lynne Hall • Ana Paiva • \\ Elisabeth André • Ruth Aylett • Wolfgang Schneider
}

Published online: 12 February 2013

(C) Instituto Superior de Psicologia Aplicada, Lisboa, Portugal and Springer Science+Business Media

Dordrecht 2013

\section{Erratum to: Eur J Psychol Educ \\ DOI 10.1007/s10212-010-0035-4.}

In the paper "FearNot!": a computer-based anti-bullying-programme designed to foster peer intervention the author group is given as: Natalie Vannini, Sibylle Enz, Maria Sapouna, Dieter Wolke, Scott Watson, Sarah Woods, Kerstin Dautenhahn, Lynne Hall, Ana Paiva, Elizabeth André, Ruth Aylett and Wolfgang Schneider. The given name of one of the authors has been spelt uncorrectly. The correct spelling is Elisabeth André. Everything else in the paper remains correct.

The online version of the original article can be found at http://dx.doi.org/10.1007/s10212-010-0035-4.

N. Vannini $\cdot$ W. Schneider

Institute of Psychology, University of Wuerzburg, Wuerzburg, Germany

N. Vannini

e-mail: natalie.vannini@psychologie.uni-wuerzburg.de

W. Schneider

e-mail: schneider@psychologie.uni-wuerzburg.de

S. Enz

Gruppe fuer Interdisziplinaere Psychologie, Universitaet Bamberg, Bamberg, Germany

e-mail: sibylle.enz@uni-bamberg.de

M. Sapouna $\cdot$ D. Wolke

Department of Psychology, University of Warwick, Coventry, UK

M. Sapouna

e-mail: maria.sapouna@scotland.gsi.gov.uk

D. Wolke

e-mail: D.Wolke@warwick.ac.uk 
S. Watson $\cdot$ S. Woods

School of Psychology, University of Hertfordshire, Hatfield, UK

S. Watson

URL: http://adapsys.feis.herts.ac.uk/

S. Woods

e-mail: s.n.woods@herts.ac.uk

K. Dautenhahn

School of Computer Science, University of Hertfordshire, Hatfield, UK

URL: http://homepages.feis.herts.ac.uk/ comqkd/

L. Hall

Department of Computing, Engineering and Technology, University of Sunderland, Sunderland, UK e-mail: lynne.hall@sunderland.ac.uk

\section{A. Paiva}

INESC-ID, Instituto Superior Técnico, Lisbon, Portugal

e-mail: ana.paiva@inesc-id.pt

\section{E. André $(\square)$}

Institut fuer Informatik, Universitaet Augsburg, Augsburg, Germany

e-mail: andre@informatik.uni-augsburg.de

R. Aylett

School of Maths and Computer Science, Heriot-Watt University, Edinburgh, UKe-mail: ruth@macs.hw.ac.uk 